\title{
Estimation of Intensity-Duration-Frequency (IDF) Curves from Large Scale Atmospheric Dataset by Statistical Downscaling
}

\author{
Khaled ALRAMLAWI ${ }^{1}$ \\ Okan FISTIKOĞLU
}

\begin{abstract}
The study proposes a new approach that combined statistical downscaling, bias correction, and disaggregation of rainfall techniques to derive the IDF curve from large scale atmospheric reanalysis data. The applied methodology details the NCEP/NCAR reanalysis dataset being downscaled by an ANN-based approach to estimate the daily rainfall of Izmir. The annual maximum rainfall series of the study area were sampled from the daily downscaled rainfall series. The sampled daily maximum rainfalls were then bias-corrected by the quantile mapping method and disaggregated into the annual maximum standardduration rainfall heights regarding the rainfalls' scale-invariant properties. Finally, the IDF curves of the study area were determined by using the disaggregated rainfall heights. The results confirmed that the IDF curves dependent on short-duration extreme rainfall heights could be reasonably estimated from the large-scale atmospheric variables using the statistical downscaling approach.
\end{abstract}

Keywords: Statistical downscaling, bias correction, quantile mapping, rainfall disaggregation, IDF curve.

\section{INTRODUCTION}

Local weather conditions of a region highly depend on the synoptic patterns evolving in three-dimensional large-scale atmospheric coverage over the region. The existing global large-scale atmospheric datasets, assimilated to better understand climate change, constructs a worldwide historical base for this large-scale coverage. The National Center for Environmental Prediction and National Center for Atmospheric Research (NCEP/NCAR) distribute reanalysis data of the global atmosphere from 1948 to the present day at $2.5^{\circ} \mathrm{X}$

\footnotetext{
Note:

- This paper was received on February 3, 2021 and accepted for publication by the Editorial Board on August 13, 2021.

- Discussions on this paper will be accepted by March 31, 2022.

- https://doi.org/10.18400/tekderg.874035

1 Dokuz Eylul University, The Graduate School of Natural And Applied Sciences, Civil Engineering Department, Izmir, Turkey - khaled.alramlawi@ogr.deu.edu.tr - https://orcid.org/0000-0002-3432-2660

2 Dokuz Eylul University, The Graduate School of Natural And Applied Sciences, Civil Engineering Department, Izmir, Turkey - okan.fistikoglu@deu.edu.tr - https://orcid.org/0000-0002-9483-1563
} 
$2.5^{\circ}$ resolution [1], while the European Centre for Medium-Range Weather Forecasts (ECMWF) produce ERA-Interim Reanalysis dataset from 1979 to today at $1.5^{\circ} \mathrm{X} 1.5^{\circ}$ resolution [2]. Both datasets have been used as observed data for explanatory data analyses in historical and/or future climate studies. Both datasets were also compared in the context of representation of regional climatic variables, such as precipitation and temperature from Asia [3] to Australia [4] and from Europe [5] to Africa [6]. The studies concluded that, in general, although each dataset performed almost similar results, the ERA-Interim dataset often reproduced slightly better observed climate relative to the NCEP/NCAR datasets due to the difference in their distinctive spatial resolutions that coarser-resolution smoothens the inter-variability of the observed climatological variables. Also, in terms of the temporal coverage, a longer period is generally preferred in most statistical analyses, and NCEP/NCAR contains 30 years more data, makes itself the preferred dataset.

Studies using reanalysis data such as NCEP/NCAR are mainly categorized into two different groups. One group regards the dataset as a benchmark relative to the estimations of the historical climate patterns of the Global Circulation Models (GCMs) [7-10], while the other group regards the dataset as independent atmospheric variables explaining the dependent local weather variables such as precipitation or temperature via quantitative estimation approaches such as linear or non-linear regression models [11-14]. The reanalysis datasets can also be used to estimate the response of a hydrological system to changing climates $[15,16]$.

The estimation of local weather variables (i.e., precipitation and temperature) from largescale atmospheric data is called downscaling. The focal point of downscaling is to transfer large-scale patterns of atmospheric variables (predictors) of either reanalysis datasets or GCMs output to local weather variables (predictands) [12,17]. Several downscaling methodologies have been developed, such as dynamical downscaling and statistical downscaling. The dynamical downscaling is associated with the physically based Regional Climate Models (RCMs), where the GCM results constitute the model domain's boundary conditions. It is computationally intensive, complex, and requires substantial computational resources $[18,19]$. Statistical downscaling utilizes statistical relationships to predict local climate variables from large-scale variables. It was developed to establish quantitative relationships between large-scale atmospheric variables and local surface variables [12]. Some of its main categories include transfer functions, weather classification methods, and weather generators $[19,20]$, with transfer functions being the most commonly used category [21]. Some examples of statistical downscaling include linear and non-linear regression, principal component analysis (PCA), canonical correlation, redundancy analysis, and Artificial Neural Networks (ANN) [12,22].

Downscaling hydro-meteorological variables result in biases inherent in the downscaling methods themselves [23] and the spatial resolution of the predictors [24-26]. These inherent biases can be removed by applying bias correction procedures on the downscaled predictands, which increases the accuracy of the results [27,28].

The statistical downscaling of hourly rainfall, required for frequency analysis of severe weather conditions, is rarely conducted because the large-scale datasets have rough temporal resolutions such as 6 hours. The majority of statistical downscaling studies focus on the estimation of monthly, daily, or annual maximum rainfall due to the temporal deficiencies of the predictor datasets [12,29-31]. 
Studies focusing on estimating sub-daily rainfall generally utilize RCMs [32] that are not practical for individual research endeavors due to their inaccessibility to the results of regional models. This impediment requires practical and functional statistical downscaling methods for the researchers dealing with the sub-daily rainfall analysis like the estimation of Intensity-Duration-Frequency (IDF) curves.

There are some reported examples in the literature of IDF curve estimation using large-scale atmospheric datasets. However, most of these reported works utilize RCMs for downscaling due to the abovementioned limitations. Mailhot et al. (2007) compared regional estimates in control and future climates on a grid box scale and reported that return periods of 2-h and 6$\mathrm{h}$ events would approximately be halved in future climates. The same study reported that return periods of 12-h and 24-h events would decrease by a third in Quebec, Canada[32]. Mirhosseini et al. (2013) reported future IDF curves of 3-hourly precipitation simulated by combining six GCMs and RCM results temporally downscaled using a stochastic method. The study evaluated the performance of downscaling methods and develop IDF curves using the RCM results for the state of Alabama, USA [33].

This paper details an approach for establishing local IDF curves using large-scale atmospheric variables. The NCEP/NCAR Reanalysis dataset over Izmir, Turkey, was used to estimate the daily rainfall values using the Artificial Neural Network (ANN)-based statistical downscaling approach. The annual maximum daily rainfall values were estimated after the bias-correction of the sampled annuals from the daily rainfall series. The annual maximum rainfall values were disaggregated based on a simple scale-invariant approach, and the maximum rainfall heights at standard durations were estimated to construct the IDF curves of the study area.

\section{STUDY AREA AND DATASETS}

Izmir, located on the Aegean coast of Turkey (see Fig. 1), was selected as the study area. It is the third-largest city in Turkey with a typical Mediterranean climate. According to the Turkish State Meteorological Service, the average annual precipitation in the area is 610 $\mathrm{mm} /$ year, and $80 \%$ of the total annual rainfall is observed in November - March period.

There are many weather stations in the study area, but only the Izmir station contains the annual maximum standard duration rainfall records. The other stations have different operation periods within the region, so their datasets were only used to validate the results of the downscaling networks of the Izmir station. The spatial locations of the stations and available datasets in the study area are summarized in Table 1 and Figure 1. The observed daily rainfall series of the Izmir stations was the predictand (output) of the downscaling networks.

The NCEP/NCAR Reanalysis dataset, as a large-scale atmospheric parameter set, is available in sub-daily, daily, and monthly time resolution for 1948 - present at a spatial resolution of $2.5^{\circ} \times 2.5^{\circ}[34]$. The daily atmospheric dataset of the NCEP/NCAR re-analysis grid, located between latitudes from $36.25^{\circ} \mathrm{N}$ to $38.75^{\circ} \mathrm{N}$, and the longitudes from $26.25^{\circ} \mathrm{E}$ to $28.75^{\circ} \mathrm{E}$ (see Figure 1), were used as predictors (inputs) of the downscaling networks. In order to validate the model, the period from 1948-1990 was used for the training period and 19912018 as the testing period. 


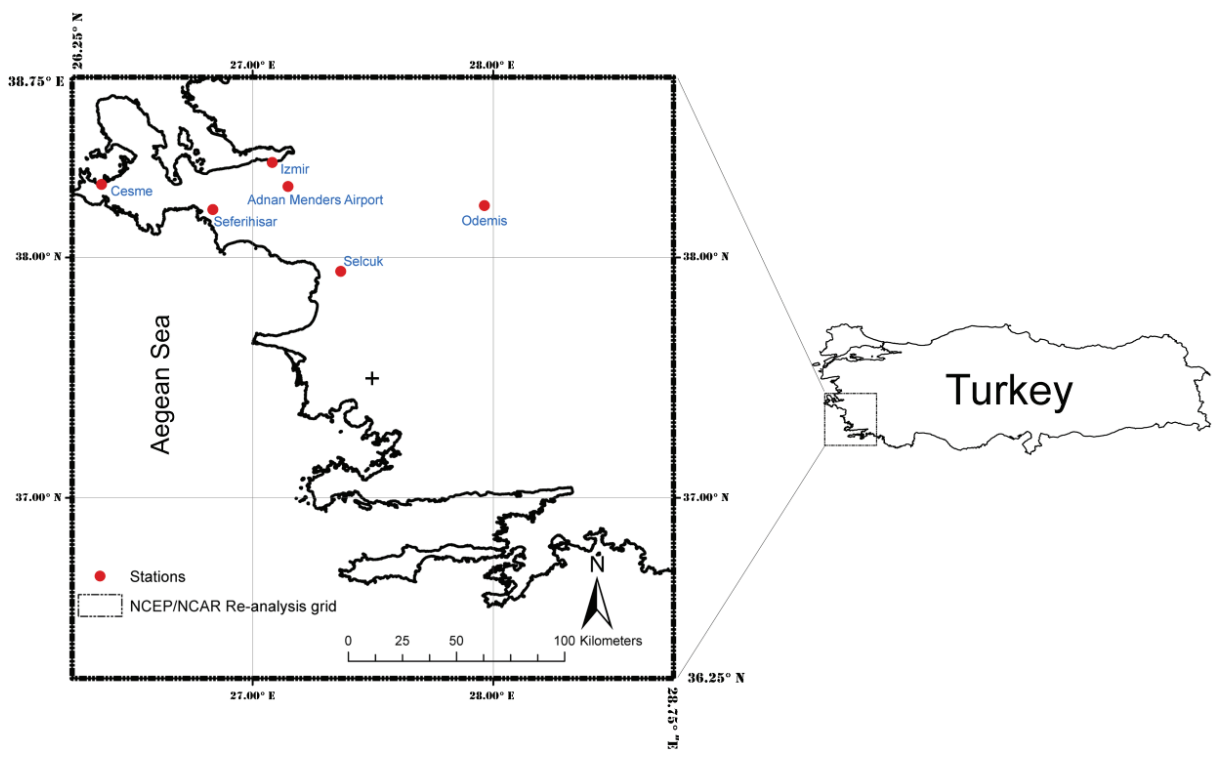

Figure 1 - Locations of the study area and selected stations

Table 1 - Meteorological stations in the study area

\begin{tabular}{cccccc}
\hline $\begin{array}{c}\text { Station } \\
\text { Number }\end{array}$ & Station Name & Latitude $\left(^{\circ}\right) \mathrm{N}$ & Longitude $\left({ }^{\circ}\right) \mathrm{E}$ & $\begin{array}{c}\text { Altitude } \\
(\mathrm{m})\end{array}$ & $\begin{array}{c}\text { Data } \\
\text { Availability }\end{array}$ \\
\hline 17220 & Izmir & 38.3949 & 27.0819 & 29 & $1938-2018$ \\
17219 & Adnan Mend. & 38.2950 & 27.1479 & 119 & $2009-2018$ \\
17820 & Seferihisar & 38.1990 & 26.8350 & 22 & $1980-2011$ \\
17221 & Cesme & 38.3036 & 26.3724 & 5 & $1965-2018$ \\
17822 & Odemis & 38.2157 & 27.9642 & 111 & $1960-2011$ \\
17854 & Selcuk & 37.9423 & 27.3669 & 18 & $1965-2011$
\end{tabular}

The first step in statistical downscaling involves selecting the appropriate predictors. Any predictor can be used for downscaling as long as it has an acceptable correlation with the predictands $[35,36]$. However, using many predictors may not result in a better relationship relative to using a parsimonious predictor set. Therefore, stepwise regression and correlation analysis, combining the inputs and outputs, can be used to select the main explanatory predictors [11,37-39].

In literature, there is not a general agreement on the selection of the most appropriate predictor variables. Generally, the selection procedure depends on the region's unique characteristics, such as its large-scale atmospheric circulation, seasonality, topography, and the predictand to be downscaled [40]. Table 2 summarizes several studies on selecting various predictors for downscaling precipitation in different regions across the world. 
Table 2 - Predictor selection in various studies

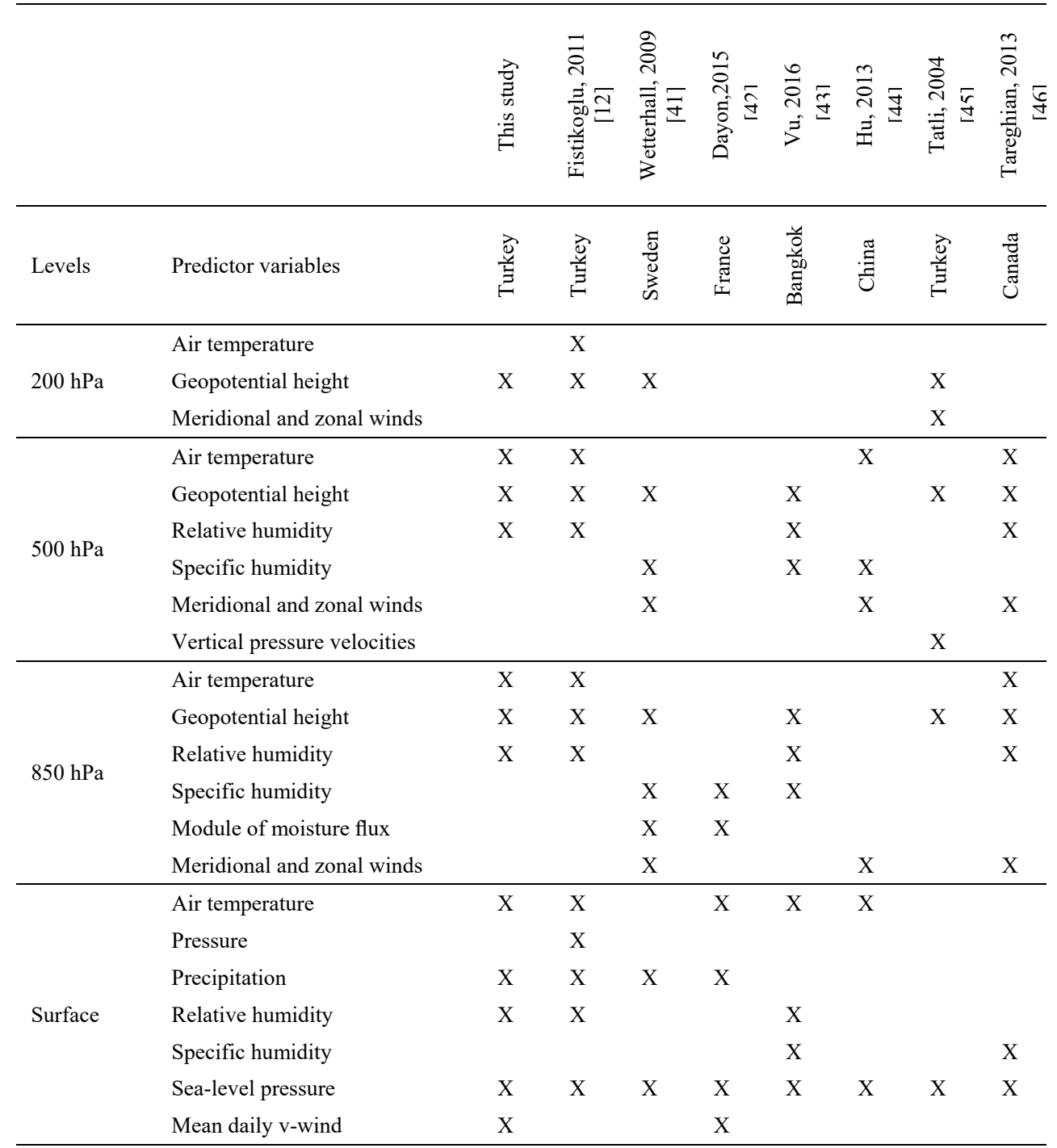

The correlation analyses depicted that the geopotential height, air temperature, relative humidity, v-wind, and mean sea level pressure play significant roles in daily rainfall events in the studied area. The predictors were then selected based on the i) acceptable correlation with the predictand and ii) the preference in the previous downscaling studies in the region. Several ANN models were constructed between the selected predictors and the daily rainfall series to determine which predictors are better suited for downscaling networks. As a result, 12 atmospheric variables from the NCEP/NCAR Reanalysis dataset listed in Table 3 were selected as predictors for the study area. 
Table 3 - Selected atmospheric predictors from NCEP/NCAR Reanalysis dataset

\begin{tabular}{clcl}
\hline Atmospheric level & \multicolumn{1}{c}{ Selected variables } & Unit & \multicolumn{1}{c}{ Abbreviation } \\
\hline \multirow{2}{*}{$500 \mathrm{hPa}$} & Mean daily geopotential height & $\mathrm{m}$ & Hgt200 \\
\hline \multirow{3}{*}{$500 \mathrm{hPa}$} & Mean daily air temperature & $\mathrm{K}$ & Air500 \\
& Mean daily geopotential height & $\mathrm{m}$ & Hgt500 \\
& Mean daily relative humidity & $\%$ & Rhum500 \\
\hline \multirow{3}{*}{$850 \mathrm{hPa}$} & Mean daily air temperature & $\mathrm{K}$ & Air850 \\
& Mean daily geopotential height & $\mathrm{m}$ & Hgt850 \\
& Mean daily relative humidity & $\%$ & Rhum850 \\
& Mean daily air temperature & $\mathrm{K}$ & Air \\
& Mean daily sea-level pressure & Pascal & Slp \\
& Mean daily relative humidity & $\%$ & Rhum \\
& Mean daily v-wind at $10 \mathrm{~m}$ & $\mathrm{~m} / \mathrm{s}$ & V-wind \\
& Mean daily precipitation rate & $\mathrm{kg} / \mathrm{m}^{2}$ & Prate \\
\hline
\end{tabular}

\section{METHODOLOGY}

The methodology of this study is summarized in Figure 2. The first step involves constructing three downscaled ANN models of the large-scale NCEP/NCAR Reanalysis data into stationbased daily rainfall series within the study area. The best ANN structure is then determined based on the performance yield from statistical analysis (e.g., $\mathrm{R}^{2}$, RMSE). The second step entails correcting the biases of the estimated annual maximum daily rainfall values sampled from the daily rainfall series downscaled by the best ANN model. This step is followed by estimating the annual 24-hour maximum rainfall values from the annual maximum daily values using the observed ratio. The final step is to disaggregate the annual 24-hour maximum rainfall into the standard-duration rainfall depths according to the scale-invariant properties of the short-duration rainfall, then estimate the IDF curves of the studied area using the probability distribution functions fitted to the standard-duration rainfall heights. Details for each step are outlined in the following sections.

\subsection{Estimation of Daily Rainfall Series Using Ann-Based Downscaling Approach}

ANN was used as a well-known machine learning technique to estimate the observed daily rainfall from the large-scale atmospheric reanalysis variables [36]. The ANN is utilized as a practical black-box tool for developing a non-linear regression between the atmospheric dataset (predictors) and observed daily rainfall (predictands) [20,47]. The earlier studies $[36,47]$ concluded that ANN is not the best statistical approach due to its exclusion of the atmospheric variables of the antecedent days as inputs and the lack of bias correction of the downscaled estimations. However, ANN proved to be one of the best alternatives in the statistical downscaling approaches when bias correction is applied to the statistically downscaled atmospheric variables $[43,48]$. Details of the ANN-based downscaling method are reported by Fistikoglu and Okkan (2011), and its applications in hydrological science are reviewed in the report of ASCE [49]. ANNs were used effectively for the daily rainfall and monthly rainfall estimations $[16,43,50]$. 


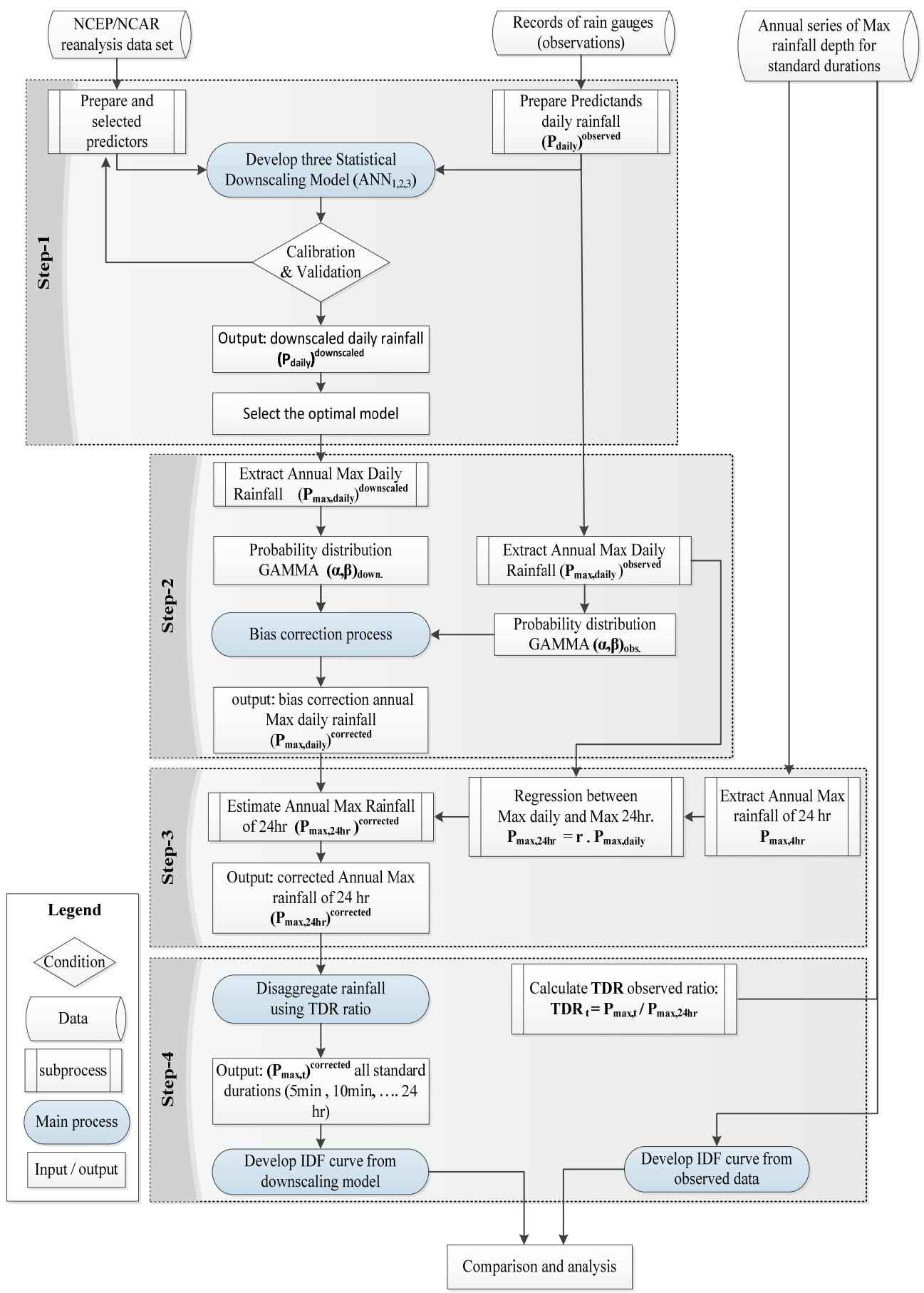

Figure 2 - The flow chart of the methodology 
As past and present large-scale atmospheric conditions significantly influence the current local weather conditions, the present and antecedent large-scale atmospheric variables were considered as inputs of the daily downscaling networks [51]. Three statistical downscaling models were tested regarding the antecedent atmospheric conditions in this study, as shown in Fig. 3.



Figure 3 - Three alternative ANN-based downscaling models tested in the study

In the first model $\left(\mathrm{ANN}_{1}\right)$, the daily atmospheric variables on the day $(\mathrm{t})$ are used as input (predictors) for estimating the daily rainfall on the day $(\mathrm{t})$. In the second model $\left(\mathrm{ANN}_{2}\right)$, the atmospheric variables of the previous $(\mathrm{t}-1)$ and current $(\mathrm{t})$ day are used as predictors, while the variables of the two antecedent days $(\mathrm{t}-2)$ are added in the final model $\left(\mathrm{ANN}_{3}\right)$. Figure 3 shows the three downscaling models based on the input variables of NCEP/NCAR dataset.

The coefficient of determination $\left(\mathrm{R}^{2}\right)$ and the root mean squared errors (RMSE) were utilized to evaluate the performance of the downscaling models and to select the optimal model structure to be used for estimating the daily rainfall in the study area.

\subsection{Bias Correction of the Annual Maximum Daily Rainfall}

The annual maximum daily rainfall is a sub-sample of the daily rainfall series. The maximum value of each year was sampled among the downscaled daily rainfall series to construct the annual maximum daily rainfall estimations. Biases emerge from the input dataset of the downscaling networks that do not represent the existing atmospheric conditions due to the spatial and temporal discrepancies, or they are caused by systematic errors depending on the structure of the downscaling networks. Therefore, the outputs of the downscaling network were evaluated based on whether their respective biases were apparent, and if they are significant, they must be removed from the downscaled series. Teutschbein and Seibert [28] evaluated bias correction methods and reported that the distribution mapping is the best method, where its core concept involves correcting the downscaled outputs based on the observed probability distribution function, which can be realized by shifting the downscaled model's outputs to the observed records with the same probability of non-exceedance [52]. The distribution mapping approach is also called quantile mapping in other studies [53-55]. 
Eqs. 1 and 2 summarize the distribution mapping method for bias correction used in this study. Figure 4 also illustrates this method with respect to the distribution functions.

$F_{\text {downscaled }}=C D F_{\text {downscaled }}\left(P_{\text {max.daily,downscaled }} \mid \alpha_{\text {downscaled }}\right)$

$P_{\text {max,daily,corrected }}=C D F_{\text {observed }}^{-1}\left(F_{\text {downscaled }} \mid \alpha_{\text {observed }}\right)$

where;

$F_{\text {downscaled }}$, is non-exceedance probability of the downscaled annual maximum daily rainfall, $C D F_{\text {downscaled }}\left(. \mid \alpha_{\text {downscaled }}\right)$ is cumulative distribution function with the parameter $\alpha_{\text {downscaled }}$ fitted to the downscaled annual maximum daily rainfall, $P_{\text {max.daily,downscaled }}$ is downscaled annual maximum daily rainfall, $C D F_{\text {observed }}^{-1}\left(. \mid \alpha_{\text {observed }}\right)$ is inverse cumulative distribution function with the parameters $\alpha_{\text {observed }}$ fitted to the observed annual maximum daily rainfall and $P_{\text {max.daily,corrected }}$ is bias-corrected annual maximum daily rainfall.

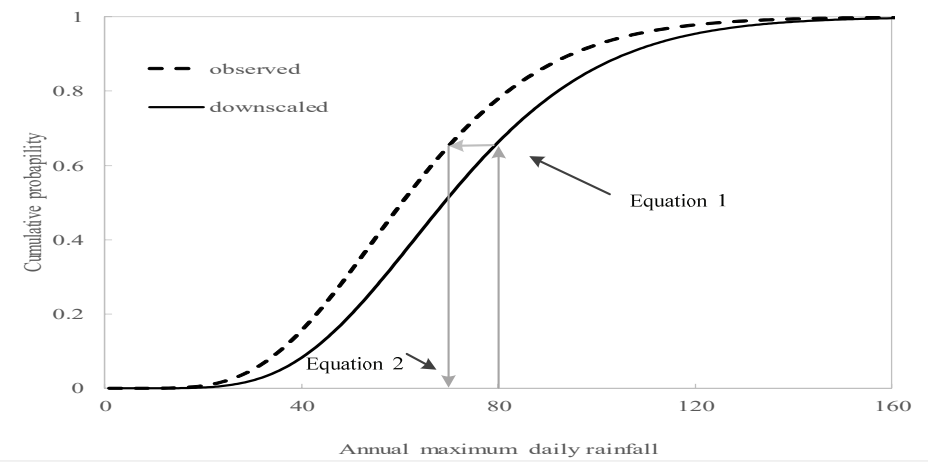

Figure 4 - Distribution mapping method for bias correction

\subsection{Estimation of the Annual Maximum 24-hour Rainfall}

The annual maximum daily rainfall $\left(P_{\text {max } \text {,daily }}\right)$ is slightly different from the annual 24-hour maximum rainfall $\left(P_{\max , 24}\right)$. The $P_{\max \text {, daily }}$ is the annual maximum rainfall height observed in a calendar day, while the $P_{\max , 24}$ the rainfall height observed in 24-hour durations that might not overlap with the calendar day duration. Although they might be different rain events, most heavy rain heights are observed in 24 hours also occur on a calendar day as it starts and ends on a calendar day. In some rare cases, it starts on a calendar day and extends to the next calendar day. Thus, the empirical ratio between $P_{\operatorname{max.24}}$ and $P_{\text {max.daily }}$ is slightly bigger than 1.0 and given in Eq. 3 .

$r=P_{\text {max.24 }} / P_{\text {max.daily }} \quad r \geq 1.0$ 
The empirical ratio $(r)$ between $P_{\max .24}$ and $P_{\text {max.daily }}$ can be estimated from the local pluviograph records. For example, $r$ is reported as 1.13 for the USA by National Weather Service, and this ratio is nearly similar within a large spatial coverage in the USA [56]. Therefore, using the empirical relationship given in Eq. 3 for the study area facilitates predicting the annual maximum 24-hour rainfall from the annual maximum daily rainfall $P_{\text {max,daily }}$. The ratio $\mathrm{r}$ can be obtained from any stations with the pluviograph observations in the study area. If the observations do not exist for a particular area, they can be transferred from the nearest station where the observations are available in the region, as it does not change dramatically over the region [56].

\subsection{Disaggregation of $\boldsymbol{P}_{\max .24}$ to Shorter Standard Duration Rainfall $\boldsymbol{P}_{\max . d}$ and IDF Curve Estimation}

The establishment of IDF curves requires rainfall heights with durations shorter than 24 hours. Short duration rainfalls, called standard duration rainfalls, are the observed annual maximum rainfall heights for each standard duration, such as 5 mins, 10 mins, 15 mins, 30 mins, 1 hour,.., 24 hours. Determining the maximum rainfall heights at standard duration $d$ requires calculating the maximum slope $(\Delta P / d)$ on each year's pluviograph records. If the pluviograph records do not exist, empirical ratios between standard duration rainfall and 24hour rainfall can be used to estimate the standard duration maximum rainfall. Those ratios can be formulated using the median values of the observed ratios, which are based on the scale-invariant rainfall models in literature [57-59].

The shorter duration annual maximum rainfalls are non-linearly proportional to the annual maximum 24-hour rainfall's height [60]. The Indian Meteorological Department (IMD) uses an empirical formula (Equation 4) to estimate the empirical ratios of short-duration rainfalls to 24-hour rainfall if the observations do not exist [61]. Chowdhury et al. [62] and Jahnvi et al. [63] used Eq. 4 to estimate the shorter rainfall intensity of any return period in their studies.

$P_{\text {max.d }}=P_{\max .24}\left(\frac{d}{24}\right)^{(1 / 3)}$

Huff and Angel analyzed records of 34 rain gauges in Illinois, USA, then propose the empirical ratio for every duration to estimate short duration rainfall from daily rainfall [56]. The proposed ratios in their study are quite like the ratios estimated from Eq. 4.

In this study, the mean values of the observed ratios of each year, which we refer to Temporal Distribution of Maximum Rainfall (TDR), are used to disaggregate the $P_{\text {max.24 }}$ to shorter standard-duration rainfall heights $P_{\text {max.d }}$ (i.e., 5-min, 10-min, 15-min, 30-min, 1-hr, 2-hr, 4$\mathrm{hr}, 6-\mathrm{hr}, 12-\mathrm{hr}, 18-\mathrm{hr}$ ). The TDR given in Eq. 5 is also compared to test the validity of both the IMP method (Eq. 4) and the empirical ratios proposed by Huff and Angel [56].

$T D R_{d}=\frac{\left(\sum_{1}^{n} P_{\max , d}\right) / n}{\left(\sum_{1}^{n} P_{\max , 24}\right) / n}$

where $T D R_{d}$ is the observed mean ratio of the annual maximum rainfall with duration $(d)$ $P_{\max , d}$ to annual maximum 24-hour rainfall $P_{\max , 24}, \mathrm{n}$ is the number of observations. If the 
observed ratios are not available in a particular area due to the lack of standard duration rainfall observations, the ratios of the nearest station in the region can be used like the case of the ratio of the daily and 24-hour maximum rainfall.

The Intensity-Duration-Frequency (IDF) curves represent the relationship between intensity, duration, and return period of the maximum rainfall height within an area [62]. The curves make it easier to compute the rainfall intensity of maximum rainfall event with different duration and the probability of exceedance, which are significant input to design urban drainage systems. The IDF curve establishment requires fitting a theoretical probability distribution to the annual maximum rainfall heights for each standard duration to calculate the return periods of them. Then, the estimated annual maximum rainfall intensities with different durations but the same return period are plotted as curves [63].

\section{RESULTS}

\subsection{Downscaling of the Daily Rainfall}

Using the large-scale atmospheric variables of the study area given in Table 3, three alternative ANN-based downscaling models were established considering the time lag configuration of the inputs as described in the section 3.1. The coefficient of determination $\left(\mathrm{R}^{2}\right)$ and the root mean squared error (RMSE) were utilized to evaluate three downscaling models. Table 4 summarizes the results of three alternative downscaling ANN structures of the Izmir station and gives the $\mathrm{R}^{2}$ between downscaled daily rainfall values and observations of the neighbor stations. Fig. 5 shows the overall performances of three downscaling models for the Izmir station as scatter diagrams. Table 4 and Fig. 5 clearly show that the second model $\left(\mathrm{ANN}_{2}\right)$, where the inputs are the atmospheric variables of the previous and current day, has better performance than the other models. It is also evident that the performance of the first model $\left(\mathrm{ANN}_{1}\right)$ produced the worst results, while the third model $\left(\mathrm{ANN}_{3}\right)$ shows no significant difference relative to the optimal model $\left(\mathrm{ANN}_{2}\right)$. Table 4 also highlights the performance of the models as $\mathrm{R}^{2}$ regarding the observations of each neighbor station. The high $\mathrm{R}^{2}$ indicates that the $\mathrm{ANN}_{2}$ based downscaled daily rainfall of the Izmir station is also spatially consistent with the observations of near stations in the region.

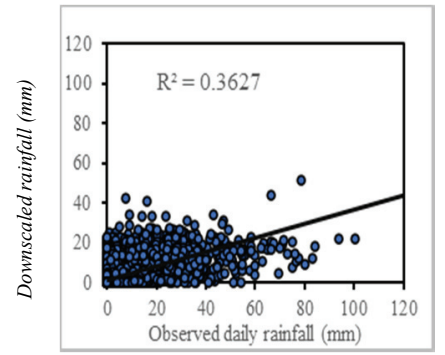

$A N N_{1}$

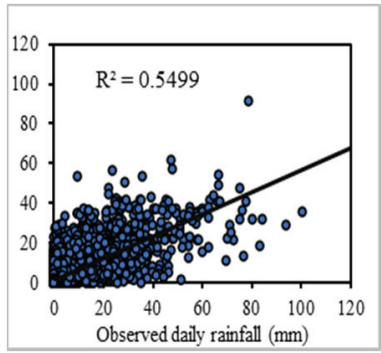

$A N N_{2}$

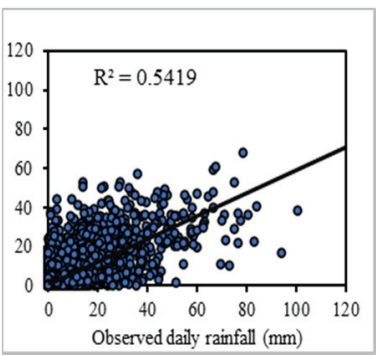

$\mathrm{ANN}_{3}$

Figure 5 - Comparison of the observed and the downscaled daily rainfall series resulted from three alternative models for the Izmir station at all training and testing period 
Table 4 - Results of the three downscaling models for the training and testing periods for each meteorological station

\begin{tabular}{|c|c|c|c|c|c|}
\hline Station & Period & Indicators & $\mathrm{ANN}_{1}$ & $\mathrm{ANN}_{2}$ & $\mathrm{ANN}_{3}$ \\
\hline \multirow{2}{*}{ Izmir } & Train & $\mathrm{R}^{2}$ & 0.363 & $\underline{0.550}$ & 0.542 \\
\hline & $1948-1990$ & RMSE & 5.256 & $\underline{4.410}$ & 4.460 \\
\hline \multirow{2}{*}{ Izmir } & Test & $\mathrm{R}^{2}$ & 0.331 & $\underline{0.462}$ & 0.451 \\
\hline & $1991-2018$ & RMSE & 5.91 & $\underline{5.250}$ & 5.330 \\
\hline A. Menderes & $\begin{array}{c}\text { Test } \\
2009-2018\end{array}$ & $\mathrm{R}^{2}$ & 0.372 & $\underline{0.507}$ & 0.487 \\
\hline Seferihisar & $\begin{array}{c}\text { Test } \\
1980-2011\end{array}$ & $\mathrm{R}^{2}$ & 0.257 & $\underline{0.351}$ & 0.348 \\
\hline Cesme & $\begin{array}{c}\text { Test } \\
1965-2018\end{array}$ & $\mathrm{R}^{2}$ & 0.267 & $\underline{0.327}$ & 0.322 \\
\hline Odemis & $\begin{array}{c}\text { Test } \\
1960-2011\end{array}$ & $\mathrm{R}^{2}$ & 0.278 & $\underline{0.408}$ & 0.366 \\
\hline Selcuk & $\begin{array}{c}\text { Test } \\
1965-2011\end{array}$ & $\mathrm{R}^{2}$ & 0.329 & $\underline{0.442}$ & 0.427 \\
\hline
\end{tabular}

\subsection{Estimation of Annual Maximum Daily Rainfall and Bias Correction}

After daily rainfall values were downscaled by $\mathrm{ANN}_{2}$ model, the maximum rainfall value in each year was sampled to construct the annual maximum daily rainfall series. As the output of the downscaling model contains biases caused by the discrepancy between the real and representative NCEP/NCAR atmospheric conditions and the inadequate model structure of the downscaling network, the biases must be removed from the annual maximum daily rainfall values. The annual maximums sampled from the daily rainfall series are as accurate as the daily estimations. Fig. 6(a) shows the observed and estimated annual maximum daily rainfall values as well as the large-scale precipitation variable of the NCEP/NCAR reanalysis dataset. Although the observed and estimated values show similar fluctuations, the biases are apparent in the estimations. Figure 6(a) also shows that both observed and downscaled annual maximum daily rainfall have approximately the same increasing trend pattern over time. This result indicates that despite the biases in the large-scale atmospheric variables, the $\mathrm{ANN}_{2}$ model structure preserves the trend mechanism in the observed rainfall series.

For bias correction, the distribution mapping method which proposed by Teutschbein and Seibert [28] was used. The cumulative distribution function of the observed and estimated annual maximum daily rainfall was considered as Gamma after the distribution analyses. The bias corrections of the annual maximum rainfall values were realized by Eq. 6 .

$P_{\text {max,daily }}^{\text {corrected }}=F_{\gamma}^{-1}\left\{F_{\gamma}\left(P_{\text {max,daily }}^{\text {downscaled }} \mid \alpha_{\text {downscaled }}, \beta_{\text {downscaled }}\right) \mid \alpha_{\text {observed }}, \beta_{\text {observed }}\right\}$ 
where; $P_{\text {max,daily }}^{\text {corrected }}$ is bias-corrected annual maximum daily rainfall, $P_{\text {max,daily }}^{\text {downscaled }}$ is downscaled annual maximum daily rainfall sampled from the daily series, $\alpha$ and $\beta$ are the shape and scale parameters of the Gamma distribution, respectively. The values of the $\alpha$ and $\beta$ are $7.16,8.84$ for the observed, and 6.82, 9.29 for the downscaled values, respectively.
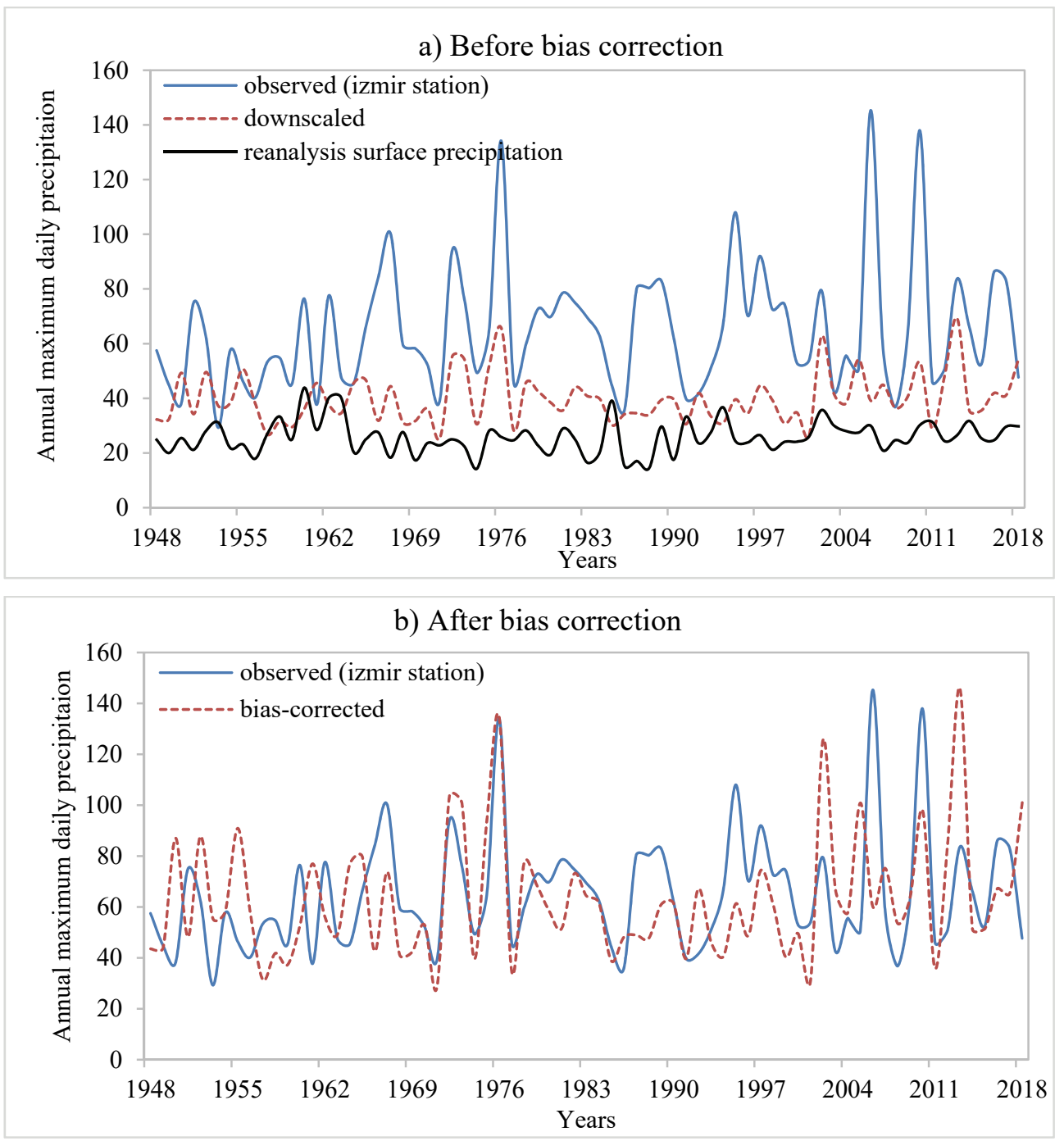

Figure 6 - a) The observed and downscaled annual maximum daily rainfall (before bias correction) and reanalysis daily precipitation at surface level b) the observed and biascorrected annual maximum daily rainfall 
Figure 6(b) exhibits the observed and bias corrected annual maximum daily rainfall values of the Izmir station. Figure indicates that bias correction stretches and shifts the downscaled annuals regarding the mean value and the distribution of the observations properly. In Figure 6(b), it is apparent that bias correction still preserves the trend mechanism in the maximum daily rainfall series. Table 5 also gives the statistics of the observed, downscaled (uncorrected), and bias corrected annual maximum daily rainfall values of the Izmir station. In addition to Table 5, Figure 7 also shows the box plot diagrams of the observed, downscaled, and bias corrected annual maximum daily rainfall $P_{\max \text {,daily }}$ of the study area. Table 5 and Fig. 7 indicate that the bias correction applies a decent correction to the downscaled maximums and the corrected maximums fairly fit to the observations.

Table 5 - Statistical parameters of annual maximum daily rainfall $\left(P_{\text {max,daily }}\right)$ of observed, downscaled and bias-corrected

\begin{tabular}{cccc}
\hline & $\begin{array}{c}P_{\text {max,daily }} \\
\text { Observed }\end{array}$ & $\begin{array}{c}P_{\text {max,daily }} \\
\text { Downscaled }\end{array}$ & $\begin{array}{c}P_{\text {max,daily }} \\
\text { Bias corrected }\end{array}$ \\
\hline $\mathrm{N}$ & 71 & 71 & 71 \\
\hline Mean & 63.35 & 41.44 & 63.30 \\
\hline Median & 59.70 & 40.70 & 61.11 \\
\hline St. Dev & 23.67 & 11.62 & 23.94 \\
\hline RMSE & & 31.76 & 28.39 \\
\hline
\end{tabular}



Figure 7 - The box plot of the observed, downscaled, and the bias-corrected annual maximum daily rainfall $P_{\text {max, daily }}$ in the Izmir station

\subsection{Estimation Annual Maximum 24-hour Rainfall}

The observed annual maximum daily rainfall values were compared with observed annual maximum 24-hour rainfall obtained from the station pluviograph records during 1948-2018. The scatter diagram (Fig. 8) of the maximum daily and 24-hour rainfall demonstrates that most of the 24-hour rainfall event occurs in a calendar day and the 24-hour maximum 
precipitation is slightly higher than the maximum daily rainfall. The regression equation between the observed daily and 24-hour rainfall observations given in Fig. 8 is used to estimate 24-hour maximum precipitation after bias corrected daily maximum rainfall is estimated.

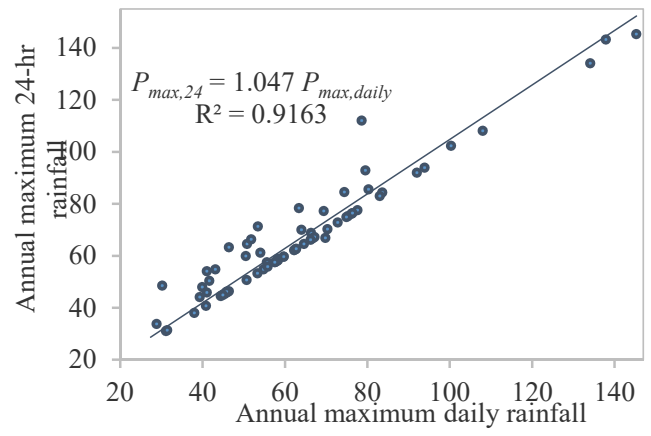

Figure 8 - The relation between $P_{\max , 24}$ and $P_{\max , \text { daily }}$

The regression equation $P_{\max , 24}=1.047 P_{\max \text {,daily }}$ for the study area is consistent with the results of the Huff and Angel [56] in USA, which show that the ratio between $P_{\max , 24}$ and $P_{\text {max,daily }}$ vary in $1.01-1.13$. The reason of these rates are so close to each other is that the 24-hour maximum rainfall usually occurs within a calendar day. Therefore, the empirical ratio (1.047) between the annual maximum 24-hour and daily rainfall, which is slightly higher than 1.0 , can be used to estimate the $P_{\max , 24}$ by using the daily maximum rainfall in the study area.

\subsection{Disaggregate Maximum 24-hour Rainfall into Standard Durations}

The maximum rainfall intensities at standard durations generally occur during the maximum 24-hour rainfall event. Several studies $[61,64,65]$ used this assumption to formulate a correlation between the standard duration rainfall and 24-hour rainfall heights.

Fig. 9 compares the disaggregation methods of the annual maximum 24-hour rainfall, IMD empirical method, observed TDR ratios in the study area, and Huff and Angel's empirical ratios. It can be seen that the observed ratios (TDR), which is used in this study, is almost similar to the IMD empirical formula [61] and also Huff and Angel's empirical ratios in the USA [56].

The observed mean of TDR values was used to disaggregate the maximum 24-hour rainfall into the values at standard duration $(5,10,15$, and 30 mins, and 1, 2, 3, 4, 5, 6, 8, 12, $18 \mathrm{hr}$ ) rainfall heights. The disaggregated values were also tested for their median and distribution properties using the Mann Whitney-U test. The basic statistics and the Mann-Whitney test of the observed and disaggregated standard duration rainfall are tabulated in Table 6. The pvalues of the Mann Whitney-U tests reveal that the differences between the median value of the observed and disaggregated standard duration rainfall heights are statistically insignificant at risk of 0.05 (see Table 6). Fig. 10 also shows the comparison between the median and distribution of the standard duration rainfall heights in the form of box plots. 


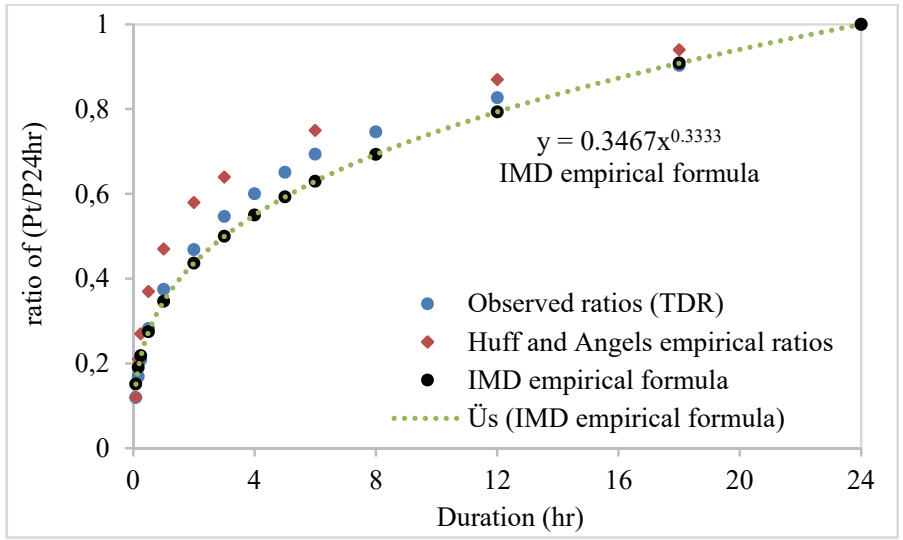

Figure 9 - Comparison of the three disaggregation methods

Table 6 - The basic statistics of the observed and disaggregated standard duration rainfall series and results of Mann-Whitney U tests

\begin{tabular}{|c|c|c|c|c|c|c|c|}
\hline $\begin{array}{l}\text { Standard } \\
\text { Duration }\end{array}$ & & Mean & Max & Min & St.dev & Skewness & $\begin{array}{c}\text { Mann-Whitney } \\
(\text { P-value }) *\end{array}$ \\
\hline \multirow{2}{*}{$5 \mathrm{~min}$} & obs. & 8.26 & 22.57 & 2.50 & 3.09 & 1.48 & \multirow{2}{*}{0.0601} \\
\hline & dis. & 7.70 & 19.60 & 3.74 & 3.06 & 1.77 & \\
\hline \multirow{2}{*}{$10 \mathrm{~min}$} & obs. & 11.59 & 31.66 & 3.10 & 4.33 & 1.48 & \multirow{2}{*}{0.0864} \\
\hline & dis. & 10.90 & 29.70 & 5.24 & 4.35 & 1.87 & \\
\hline \multirow{2}{*}{$15 \mathrm{~min}$} & obs. & 14.25 & 38.93 & 4.30 & 5.32 & 1.48 & \multirow{2}{*}{0.0816} \\
\hline & dis. & 13.50 & 37.40 & 6.45 & 5.43 & 1.80 & \\
\hline \multirow{2}{*}{$30 \mathrm{~min}$} & obs. & 19.02 & 51.96 & 6.00 & 7.11 & 1.48 & \multirow{2}{*}{0.0732} \\
\hline & dis. & 18.20 & 52.30 & 8.61 & 7.81 & 1.85 & \\
\hline \multirow{2}{*}{$1 \mathrm{hr}$} & obs. & 24.94 & 68.13 & 9.10 & 9.32 & 1.48 & \multirow{2}{*}{0.0983} \\
\hline & dis. & 24.20 & 60.80 & 11.29 & 10.99 & 1.56 & \\
\hline \multirow{2}{*}{$2 \mathrm{hr}$} & obs. & 30.90 & 84.40 & 11.20 & 11.54 & 1.48 & \multirow{2}{*}{0.1278} \\
\hline & dis. & 30.20 & 76.50 & 13.98 & 13.57 & 1.45 & \\
\hline \multirow{2}{*}{$3 \mathrm{hr}$} & obs. & 35.54 & 97.07 & 14.80 & 13.27 & 1.48 & \multirow{2}{*}{0.1327} \\
\hline & dis. & 35.30 & 83.50 & 16.08 & 15.23 & 1.58 & \\
\hline \multirow{2}{*}{$4 \mathrm{hr}$} & obs. & 39.09 & 106.77 & 16.70 & 14.60 & 1.48 & \multirow{2}{*}{0.146} \\
\hline & dis. & 38.70 & 92.60 & 17.69 & 15.52 & 1.53 & \\
\hline \multirow{2}{*}{$5 \mathrm{hr}$} & obs. & 42.23 & 115.35 & 17.50 & 15.77 & 1.48 & \multirow{2}{*}{0.1097} \\
\hline & dis. & 42.00 & 115.70 & 19.11 & 17.51 & 1.93 & \\
\hline \multirow{2}{*}{$6 \mathrm{hr}$} & obs. & 44.87 & 122.55 & 18.50 & 16.76 & 1.48 & \multirow{2}{*}{0.1259} \\
\hline & dis. & 44.80 & 132.90 & 20.30 & 18.67 & 2.30 & \\
\hline \multirow{2}{*}{$8 \mathrm{hr}$} & obs. & 48.02 & 131.17 & 18.50 & 17.94 & 1.48 & \multirow{2}{*}{0.2127} \\
\hline & dis. & 48.20 & 144.90 & 21.73 & 19.63 & 2.37 & \\
\hline \multirow{2}{*}{$12 \mathrm{hr}$} & obs. & 52.84 & 144.34 & 18.50 & 19.74 & 1.48 & \multirow{2}{*}{0.2043} \\
\hline & dis. & 53.40 & 145.10 & 23.91 & 21.30 & 1.91 & \\
\hline \multirow{2}{*}{$18 \mathrm{hr}$} & obs. & 57.32 & 156.56 & 18.50 & 21.41 & 1.48 & \multirow{2}{*}{0.3097} \\
\hline & dis. & 58.30 & 145.30 & 25.94 & 22.47 & 1.58 & \\
\hline \multirow{2}{*}{$24 \mathrm{hr}$} & obs. & 63.65 & 173.85 & 31.10 & 23.77 & 1.48 & \multirow{2}{*}{0.638} \\
\hline & dis. & 64.50 & 145.30 & 28.80 & 22.76 & 1.47 & \\
\hline
\end{tabular}

*If the p-value is greater than the significance level (0.05), the decision fails to reject the null hypothesis that the median of the observations equals the median of the estimated values. 

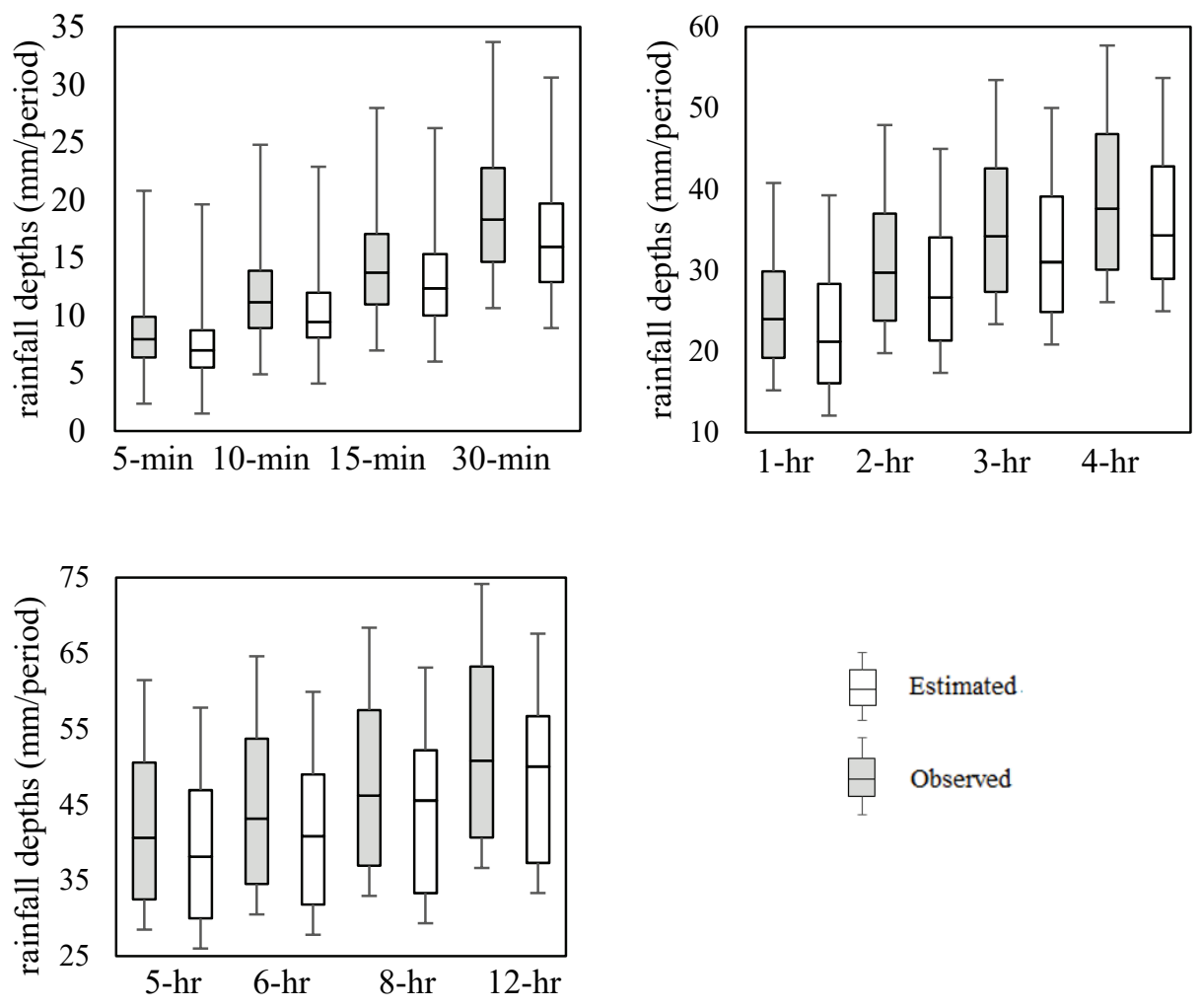

Estimated

Observed

Figure 10 - Box plots of the observed and disaggregated standard duration rainfall heights

\subsection{Observed and Estimated IDF Curves}

The observed annual maximum rainfalls for the standard durations $(5,10,15,30 \mathrm{~min}, 1,2$, $3,4,5,6,8,12$, and $24 \mathrm{hr}$ ) were analyzed to develop the IDF curves, and the 2-, 5-, 10-, 2550 - and 100-years rainfall intensities were calculated using the probability distribution function of the observed standard duration rainfalls as log-normal.

Fig. 11(a) shows the IDF curves obtained from the observed rainfall records of the Izmir station. The IDF curves can be expressed as an equation, assuming logarithmic relationships between intensities, durations, and frequencies [66]. The equation is also shown in Fig. 11(a).

Similarly, the disaggregated estimations for standard duration rainfalls were also used to construct the estimated IDF curves using the same durations and occurrences. The log-normal distribution was again selected as an appropriate probability distribution function for the estimated standard duration rainfall intensities. The estimated IDF curves and their equation form of the Izmir station are also shown in Figure 11(b). It was noticed that the observed and estimated IDF curves and their simple forms of equations are not significantly different. 


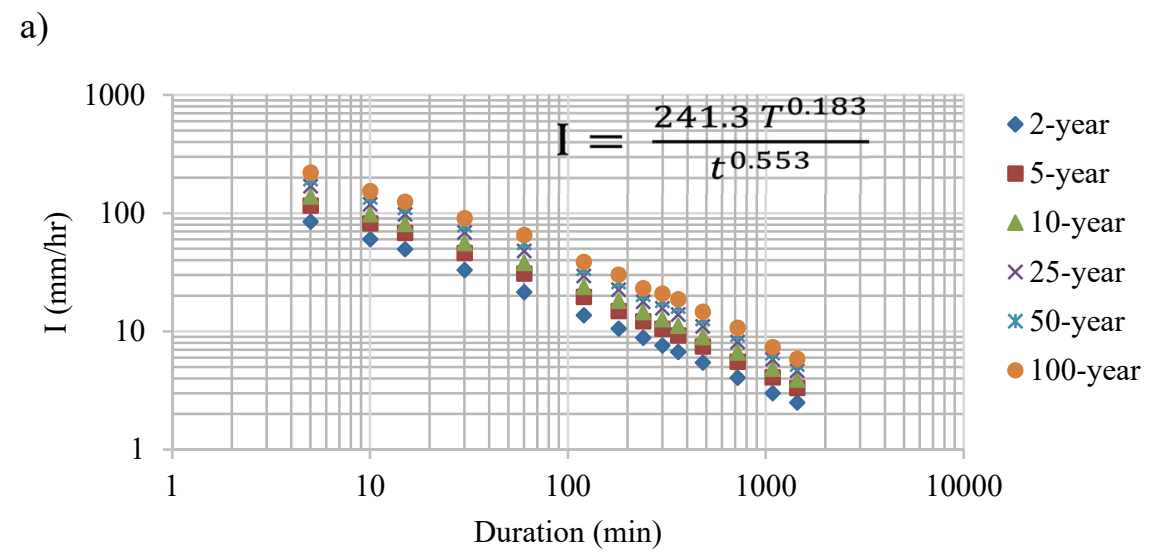

b)

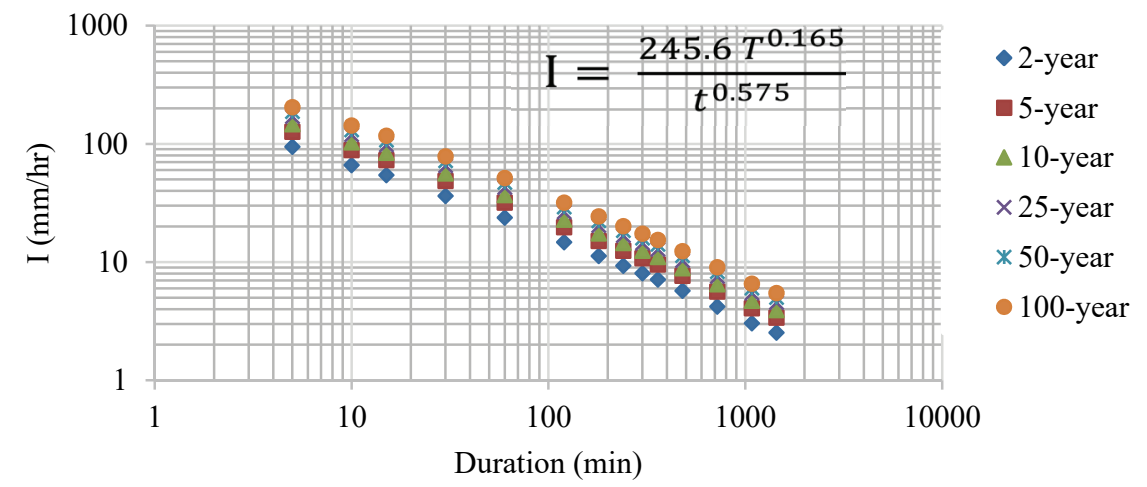

Figure 11 - IDF curves for the Izmir station (a) obtained from observed values (b) estimated from large scale atmospheric variables

\section{CONCLUSIONS}

The ANN technique was used to establish a statistical downscaling model for estimating the station-based daily rainfall values from large-scale NCEP/NCAR atmospheric variables for the city of Izmir in the Aegean region. The best downscaling model structure was achieved by using atmospheric variables of the current and previous day as predictors. The results of the model were compared with observations of the neighbor stations for spatial validation. The atmospheric variables selected as predictors such as air temperature, relative humidity, and geopotential height at different atmospheric levels and sea level pressure, v-wind, and areal precipitation rate at the surface on the current and previous day were the most explanatory variables for the daily rainfall estimations in the study area. The atmospheric conditions of the previous day were crucial as they increase the accuracy of the estimations. 
The annual maximum daily values were sampled from the downscaled daily rainfall series. The biases in the annual maximum daily values were removed using the distribution mapping approach. The results showed that the estimated annual maximum daily rainfall values were consistent with the observations in the study area, which led to the conclusion that the bias correction is a crucial step in a statistical downscaling approach. The method presented here requires the daily rainfall observations to construct a downscaling model and bias corrections. If the observations do not exist at all, it is not possible to find the relationship between large scale atmospheric variables and daily rainfall values. On the other hand, the method presented here can be used to extend the inadequate rainfall observations to estimate long term values.

The bias corrected annual maximum daily rainfall values sampled from the daily rainfall series (1948-2018) were transformed to the annual maximum 24-hour values using the observed empirical ratio. The observed empirical ratio in the study area was revealed that the 24-hour rainfall values were slightly higher than the daily maximum rainfall values. If the 24-hour rainfall values are not available in the study area, 24-hour rainfall values can be assumed as equal to the daily maximum rainfall values since the ratio is very close to one.

The estimated annual maximum 24-hour rainfall values were disaggregated into the shorter standard duration rainfall values using the mean values of the observed ratios (TDR) between 24-hour rainfall and standard duration rainfall. The Mann-Whitney U statistics revealed that the disaggregated estimations have similar medians and distributions with the observed standard duration rainfalls. The results of the disaggregation phase of the study revealed that the observed empirical ratios between the standard duration rainfall and 24-hour rainfall could be used to estimate the sub-daily rates of the maximum rainfall. The observed ratios are very close to the IMD equation, which only consider the power function of durations. If the observed standard duration rainfall records do not exist in the study area, the IMD equation can be used conveniently.

Finally, the estimated standard duration rainfall values were used to generate IDF curves, and a simple form of the IDF equation was fitted to both observed and estimated rainfall intensities. The concordance between estimated and observed IDF curves and equations indicate that the large-scale atmospheric variables can be used to estimate IDF curves reasonably if the daily rainfall values were downscaled and bias-corrected appropriately.

As the number of annual maximum values are essential for statistical analysis of the extreme rainfall events, the approach detailed here could extend the annual maximum dataset of a region where the observation period is inadequate for proper statistical data analyses. Although the methodology applied in this study estimates the IDF curves from historical atmospheric variables, it can be also used to predict future IDF curves using the atmospheric variables of the GCMs running under different climate scenarios. The bias correction of the daily rainfall predictions for the future must be realized by using the historical and future atmospheric predictions of the GCMs.

\section{Symbols}
ANN
: Artificial neural networks
$\mathrm{CDF}$
: Cumulative distribution function 


$\begin{array}{ll}\mathrm{CDF}^{-1} & : \text { Inverse cumulative distribution function } \\ \text { GCMs } & : \text { Global Circulation Models } \\ \text { IDF } & : \text { Intensity-Duration-Frequency } \\ \text { IMD } & : \text { Indian Meteorological Department } \\ \text { NCEP/NCAR } & : \text { National Center for Environmental Prediction and } \\ & \text { National Center for Atmospheric Research } \\ \text { Obs. } & : \text { Observed } \\ \text { Dow. } & : \text { Downscaled } \\ \mathrm{P}_{\text {max }, 24 h r} & : \text { Annual maximum rainfall in } 24 \text { hours } \\ \mathrm{P}_{\text {max,d }} & : \text { Annual maximum rainfall in duration d } \\ \mathrm{P}_{\text {max,daily }} & : \text { Annual maximum daily rainfall } \\ \text { RCMs } & : \text { Regional climate models } \\ \text { TDR } & : \text { Temporal distribution of rainfall } \\ \alpha, \beta & : \text { Shape and scale parameters of Gamma distribution } \\ \gamma & : \text { Gamma distribution }\end{array}$

\section{References}

[1] Kalnay, E. et al., The NCEP/NCAR 40-Year Reanalysis Project, Bull. Am. Meteorol. Soc., vol. 77, no. 3, pp. 437-471, 1996.

[2] Dee, D. P. et al., The ERA-Interim Reanalysis: Configuration and Performance of the Data Assimilation System, Q. J. R. Meteorol. Soc., vol. 137, no. 656, pp. 553-597, 2011.

[3] Wang, A. and Zeng, X., Evaluation of Multireanalysis Products with in Situ Observations over the Tibetan Plateau, J. Geophys. Res. Atmos., vol. 117, no. 5, 2012.

[4] Fu, G., Charles, S. P., Timbal, B., Jovanovic, B., and Ouyang, F., Comparison of NCEP-NCAR and ERA-Interim over Australia, Int. J. Climatol., vol. 36, no. 5, pp. 2345-2367, 2016.

[5] Mooney, P. A., Mulligan, F. J., and Fealy, R., Comparison of ERA-40, ERA-Interim and NCEP/NCAR Reanalysis Data with Observed Surface Air Temperatures over Ireland, Int. J. Climatol., vol. 31, no. 4, pp. 545-557, 2011.

[6] Druyan, L. and Fulakeza, M., Downscaling Reanalysis over Continental Africa with a Regional Model: NCEP versus ERA Interim Forcing, Clim. Res., vol. 56, no. 3, pp. 181-196, 2013. 
[7] Tolika, K., Maheras, P., Flocas, H. A., and Arseni-Papadimitriou, A., An Evaluation of a General Circulation Model (GCM) and the NCEP-NCAR Reanalysis Data for Winter Precipitation in Greece, Int. J. Climatol., vol. 26, no. 7, pp. 935-955, 2006.

[8] Plummer, D. A., Caya, D., Frigon, A., Côté, H., Giguère, M., Paquin, D., Biner, S., Harvey, R., and De Elia, R., Climate and Climate Change over North America as Simulated by the Canadian RCM, J. Clim., vol. 19, no. 13, pp. 3112-3132, 2006.

[9] Fu, G., Liu, Z., Charles, S. P., Xu, Z., and Yao, Z., A Score-Based Method for Assessing the Performance of GCMs: A Case Study of Southeastern Australia, J. Geophys. Res. Atmos., vol. 118, no. 10, pp. 4154-4167, 2013.

[10] Jiang, D., Tian, Z., and Lang, X., Reliability of Climate Models for China through the IPCC Third to Fifth Assessment Reports, Int. J. Climatol., vol. 36, no. 3, pp. 1114 $1133,2016$.

[11] Wilby, R. L., Hay, L. E., and Leavesley, G. H., A Comparison of Downscaled and Raw GCM Output: Implications for Climate Change Scenarios in the San Juan River Basin, Colorado, J. Hydrol., vol. 225, no. 1-2, pp. 67-91, 1999.

[12] Fistikoglu, O. and Okkan, U., Statistical Downscaling of Monthly Precipitation Using NCEP/NCAR Reanalysis Data for Tahtali River Basin in Turkey, J. Hydrol. Eng., vol. 16, no. 2, pp. 157-164, 2011.

[13] Brands, S., Gutiérrez, J. M., Herrera, S., and Cofiño, A. S., On the Use of Reanalysis Data for Downscaling, J. Clim., vol. 25, no. 7, pp. 2517-2526, 2012.

[14] Sachindra, D. A. and Perera, B. J. C., Statistical Downscaling of General Circulation Model Outputs to Precipitation Accounting for Non-Stationarities in PredictorPredictand Relationships, PLoS One, vol. 11, no. 12, p. e0168701, 2016.

[15] Chen, H., Xu, C. Y., and Guo, S., Comparison and Evaluation of Multiple GCMs, Statistical Downscaling and Hydrological Models in the Study of Climate Change Impacts on Runoff, J. Hydrol., vol. 434-435, pp. 36-45, 2012.

[16] Okkan, U. and Fistikoglu, O., Evaluating Climate Change Effects on Runoff by Statistical Downscaling and Hydrological Model GR2M, Theor. Appl. Climatol., vol. 117, no. 1, pp. 343-361, 2014.

[17] Liu, J., Yuan, D., Zhang, L., Zou, X., and Song, X., Comparison of Three Statistical Downscaling Methods and Ensemble Downscaling Method Based on Bayesian Model Averaging in Upper Hanjiang River Basin, Adv. Meteorol., pp. 1-12, 2016.

[18] Murphy, J., An Evaluation of Statistical and Dynamical Techniques for Downscaling Local Climate, J. Clim., vol. 12, no. 8, pp. 2256-2284, 1999.

[19] Trzaska, Y. and Schnarr, E., A Review of Downscaling Methods for Climate Change Projections (USAID, 2014), 2014.

[20] Khan, M. S., Coulibaly, P., and Dibike, Y., Uncertainty Analysis of Statistical Downscaling Methods, J. Hydrol., vol. 319, no. 1-4, pp. 357-382, 2006. 
[21] Schoof, J. T., Pryor, S. C., and Robeson, S. M., Downscaling Daily Maximum and Minimum Temperatures in the Midwestern USA: A Hybrid Empirical Approach, Int. J. Climatol., vol. 27, no. 4, pp. 439-454, 2007.

[22] Benestad, R. E., Hanssen-Bauer, I., and Førland, E. J., An Evaluation of Statistical Models for Downscaling Precipitation and Their Ability to Capture Long-Term Trends, Int. J. Climatol., vol. 27, no. 5, pp. 649-665, 2007.

[23] Cannon, A. J., Sobie, S. R., and Murdock, T. Q., Bias Correction of GCM Precipitation by Quantile Mapping: How Well Do Methods Preserve Changes in Quantiles and Extremes?, J. Clim., vol. 28, no. 17, pp. 6938-6959, 2015.

[24] Mendoza, P. A., Mizukami, N., Ikeda, K., Clark, M. P., Gutmann, E. D., Arnold, J. R., Brekke, L. D., and Rajagopalan, B., Effects of Different Regional Climate Model Resolution and Forcing Scales on Projected Hydrologic Changes, J. Hydrol., vol. 541, pp. 1003-1019, 2016.

[25] Karmacharya, J., Jones, R., Moufouma-Okia, W., and New, M., Evaluation of the Added Value of a High-Resolution Regional Climate Model Simulation of the South Asian Summer Monsoon Climatology, Int. J. Climatol., vol. 37, no. 9, pp. 3630-3643, 2017.

[26] Sun, Y., Wendi, D., Kim, D. E., and Liong, S. Y., Deriving Intensity-DurationFrequency (IDF) Curves Using Downscaled in Situ Rainfall Assimilated with Remote Sensing Data, Geosci. Lett., vol. 6, no. 1, p. 17, 2019.

[27] Christensen, J. H., Boberg, F., Christensen, O. B., and Lucas-Picher, P., On the Need for Bias Correction of Regional Climate Change Projections of Temperature and Precipitation, Geophys. Res. Lett., vol. 35, no. 20, 2008.

[28] Teutschbein, C. and Seibert, J., Bias Correction of Regional Climate Model Simulations for Hydrological Climate-Change Impact Studies: Review and Evaluation of Different Methods, J. Hydrol., vol. 456-457, pp. 12-29, 2012.

[29] Singh, V. K. and Kumar, D., Downscaling Daily Precipitation over the Upper Shivnath Basin: A Comparison of Three Statistical Downscaling Techniques, Int. J. Curr. Microbiol. Appl. Sci., vol. 9, no. 1, pp. 1676-1688, 2020.

[30] Goly, A., Teegavarapu, R. S. V., and Mondal, A., Development and Evaluation of Statistical Downscaling Models for Monthly Precipitation, Earth Interact., vol. 18, no. 18, pp. 1-28, 2014.

[31] Hung, N. Q., Babel, M. S., Weesakul, S., and Tripathi, N. K., An Artificial Neural Network Model for Rainfall Forecasting in Bangkok, Thailand, Hydrol. Earth Syst. Sci., vol. 13, no. 8, pp. 1413-1425, 2009.

[32] Mailhot, A., Duchesne, S., Caya, D., and Talbot, G., Assessment of Future Change in Intensity-Duration-Frequency (IDF) Curves for Southern Quebec Using the Canadian Regional Climate Model (CRCM), J. Hydrol., vol. 347, no. 1-2, pp. 197-210, 2007.

[33] Mirhosseini, G., Srivastava, P., and Stefanova, L., The Impact of Climate Change on Rainfall Intensity-Duration-Frequency (IDF) Curves in Alabama, Reg. Environ. Chang., vol. 13, no. SUPPL.1, pp. 25-33, 2013. 
[34] Hofer, M., Mölg, T., Marzeion, B., and Kaser, G., Empirical-Statistical Downscaling of Reanalysis Data to High-Resolution Air Temperature and Specific Humidity above a Glacier Surface (Cordillera Blanca, Peru), J. Geophys. Res. Atmos., vol. 115, no. 12, 2010.

[35] Giorgi, F., Hewitson, B., Arritt, R., Gutowski, W., Knutson, T., and Landsea, C., Regional Climate Information-Evaluation and Projections, Clim. Chang. 2001 Sci. bases, 2001.

[36] Wilby, R. L., Wigley, T. M. L., Conway, D., Jones, P. D., Hewitson, B. C., Main, J., and Wilks, D. S., Statistical Downscaling of General Circulation Model Output: A Comparison of Methods, Water Resour. Res., vol. 34, no. 11, pp. 2995-3008, 1998.

[37] Karl, T. R., Wang, W.-C., Schlesinger, M. E., Knight, R. W., and Portman, D., A Method of Relating General Circulation Model Simulated Climate to the Observed Local Climate. Part I: Seasonal Statistics, J. Clim., vol. 3, no. 10, pp. 1053-1079, 1990.

[38] Kidson, J. W. and Thompson, C. S., A Comparison of Statistical and Model-Based Downscaling Techniques for Estimating Local Climate Variations, J. Clim., vol. 11, no. 4, pp. 735-753, 1998.

[39] Chen, H., Guo, J., Xiong, W., Guo, S., and Xu, C.-Y., Downscaling GCMs Using the Smooth Support Vector Machine Method to Predict Daily Precipitation in the Hanjiang Basin, Adv. Atmos. Sci., vol. 27, no. 2, pp. 274-284, 2010.

[40] Anandhi, A., Srinivas, V. V., Kumar, D. N., and Nanjundiah, R. S., Role of Predictors in Downscaling Surface Temperature to River Basin in India for IPCC SRES Scenarios Using Support Vector Machine, Int. J. Climatol., vol. 29, no. 4, pp. 583-603, 2009.

[41] Wetterhall, F., Bárdossy, A., Chen, D., Halldin, S., and Xu, C. Y., Statistical Downscaling of Daily Precipitation over Sweden Using GCM Output, in Theoretical and Applied Climatology, May 2009, vol. 96, no. 1-2, pp. 95-103.

[42] Dayon, G., Boé, J., and Martin, E., Transferability in the Future Climate of a Statistical Downscaling Method for Precipitation in France, J. Geophys. Res. Atmos., vol. 120, no. 3, pp. 1023-1043, 2015.

[43] Vu, M. T., Aribarg, T., Supratid, S., Raghavan, S. V., and Liong, S. Y., Statistical Downscaling Rainfall Using Artificial Neural Network: Significantly Wetter Bangkok?, Theor. Appl. Climatol., vol. 126, no. 3-4, pp. 453-467, 2016.

[44] Hu, Y., Maskey, S., and Uhlenbrook, S., Downscaling Daily Precipitation over the Yellow River Source Region in China: A Comparison of Three Statistical Downscaling Methods, Theor. Appl. Climatol., vol. 112, no. 3-4, pp. 447-460, 2013.

[45] Tatli, H., Nüzhet Dalfes, H., and Sibel Menteş, A Statistical Downscaling Method for Monthly Total Precipitation over Turkey, Int. J. Climatol., vol. 24, no. 2, pp. 161-180, 2004.

[46] Tareghian, R. and Rasmussen, P. F., Statistical Downscaling of Precipitation Using Quantile Regression, J. Hydrol., vol. 487, pp. 122-135, 2013. 
[47] Harpham, C. and Wilby, R. L., Multi-Site Downscaling of Heavy Daily Precipitation Occurrence and Amounts, J. Hydrol., vol. 312, no. 1-4, pp. 235-255, 2005.

[48] Mendes, D. and Marengo, J. A., Temporal Downscaling: A Comparison between Artificial Neural Network and Autocorrelation Techniques over the Amazon Basin in Present and Future Climate Change Scenarios, Theor. Appl. Climatol., vol. 100, no. 3, pp. 413-421, 2010.

[49] ASCE, Artificial Neural Networks in Hydrology. II: Hydrologic Applications, J. Hydrol. Eng., vol. 5, no. 2, pp. 124-137, 2000.

[50] Nourani, V., Razzaghzadeh, Z., Baghanam, A. H., and Molajou, A., ANN-Based Statistical Downscaling of Climatic Parameters Using Decision Tree Predictor Screening Method, Theor. Appl. Climatol., vol. 137, no. 3-4, pp. 1729-1746, 2019.

[51] Coulibaly, P., Dibike, Y. B., and Anctil, F., Downscaling Precipitation and Temperature with Temporal Neural Networks, J. Hydrometeorol., vol. 6, no. 4, pp. 483-496, 2005.

[52] Sennikovs, J. and Bethers, U., Statistical Downscaling Method of Regional Climate Model Results for Hydrological Modelling, 2009.

[53] Ines, A. V. M. and Hansen, J. W., Bias Correction of Daily GCM Rainfall for Crop Simulation Studies, Agric. For. Meteorol., pp. 44-53, 2006.

[54] Piani, C., Haerter, J. O., and Coppola, E., Statistical Bias Correction for Daily Precipitation in Regional Climate Models over Europe, Theor. Appl. Climatol., vol. 99, no. 1-2, pp. 187-192, 2010.

[55] Johnson, F. and Sharma, A., Accounting for Interannual Variability: A Comparison of Options for Water Resources Climate Change Impact Assessments, Water Resour. Res., vol. 47, no. 4, 2011.

[56] Huff, F. A. and Angel, J. R., Rainfall Frequency Atlas of the Midwest. Bulletin (Illinois State Water Survey) No. 71, 1992.

[57] Nguyen, V. T. V., Nguyen, T. D., and Wang, H., Regional Estimation of Short Duration Rainfall Extremes, Water Sci. Technol., vol. 37, no. 11, pp. 15-19, 1998.

[58] Borga, M., Vezzani, C., and Dall Fontana, G., Regional Rainfall Depth-DurationFrequency Equations for an Alpine Region, Nat. Hazards, vol. 36, no. 1-2, pp. 221235,2005 .

[59] Bonaccorso, B., Brigandì, G., and Aronica, G. T., Regional Sub-Hourly Extreme Rainfall Estimates in Sicily under a Scale Invariance Framework, Water Resour. Manag., vol. 34, no. 14, pp. 4363-4380, 2020.

[60] Huff, F. A., Time Distribution of Rainfall in Heavy Storms, Water Resour. Res., vol. 3, no. 4, pp. 1007-1019, 1967.

[61] Al Mamun, A., bin Salleh, M. N., and Noor, H. M., Estimation of Short-Duration Rainfall Intensity from Daily Rainfall Values in Klang Valley, Malaysia, Appl. Water Sci., vol. 8, no. 7, p. 203, 2018. 
[62] Anilan, T., Yüksek, Ö., Saka, F., and Orgun, E., Rainfall Intensity-Duration-Frequency Analysis in Turkey, with the Emphasis of Eastern Black Sea Basin, Tek. Dergi, vol. 33, no. $4,2022$.

[63] Chow, T. V., Maidment, D. R., and Larry, W. M., “Applied hydrology." Water Resources Handbook; McGraw-Hill. New York, NY, USA, 1988.

[64] Chowdhury, R., Alam, M. J., Das, P., and Alam, M. A., Short Duration Rainfall Estimation of Sylhet: IMD and USWB Method, J. Indian Water Work. Assoc., vol. 39, no. 4, pp. 285-292, 2007.

[65] Jahnvi, M., Bhatt, P., Gandhi, H. M., and Gohil, K. B., Generation of Intensity Duration Frequency Curve Using Daily, J. Int. Acad. Res. Multidiscip., vol. 2, no. 2, pp. 717$722,2014$.

[66] AlHassoun, S. A., Developing an Empirical Formulae to Estimate Rainfall Intensity in Riyadh Region, J. King Saud Univ. - Eng. Sci., vol. 23, no. 2, pp. 81-88, 2011. 
